\title{
Correction to: Simultaneous sequestration of uranyl and arsenate at the goethite/water interface
}

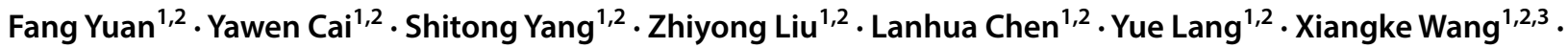 \\ Shuao Wang ${ }^{1,2}$
}

Published online: 6 March 2020

๑) Akadémiai Kiadó, Budapest, Hungary 2020

\section{Correction to: J Radioanal Nucl Chem (2017) 311:815-831 https://doi.org/10.1007/s10967-016-5086-9}

In the original publication of the article, Fig. 8 was erroneously plotted due to unintentional misoperation of batch input of the XRD data which caused the repeating patterns of Single-U5 and Single-U50 in this figure. The correct version of Fig. 8 is provided in this correction.
Fig. 8 PXRD patterns of uptake samples prepared in different cosorption systems at an aging time of 1 day. $T=293 \mathrm{~K}$, $\mathrm{pH} 5.5, m / V=0.5 \mathrm{~g} / \mathrm{L}$, $C_{\mathrm{NaNO}_{3}}=0.01 \mathrm{~mol} / \mathrm{L}$

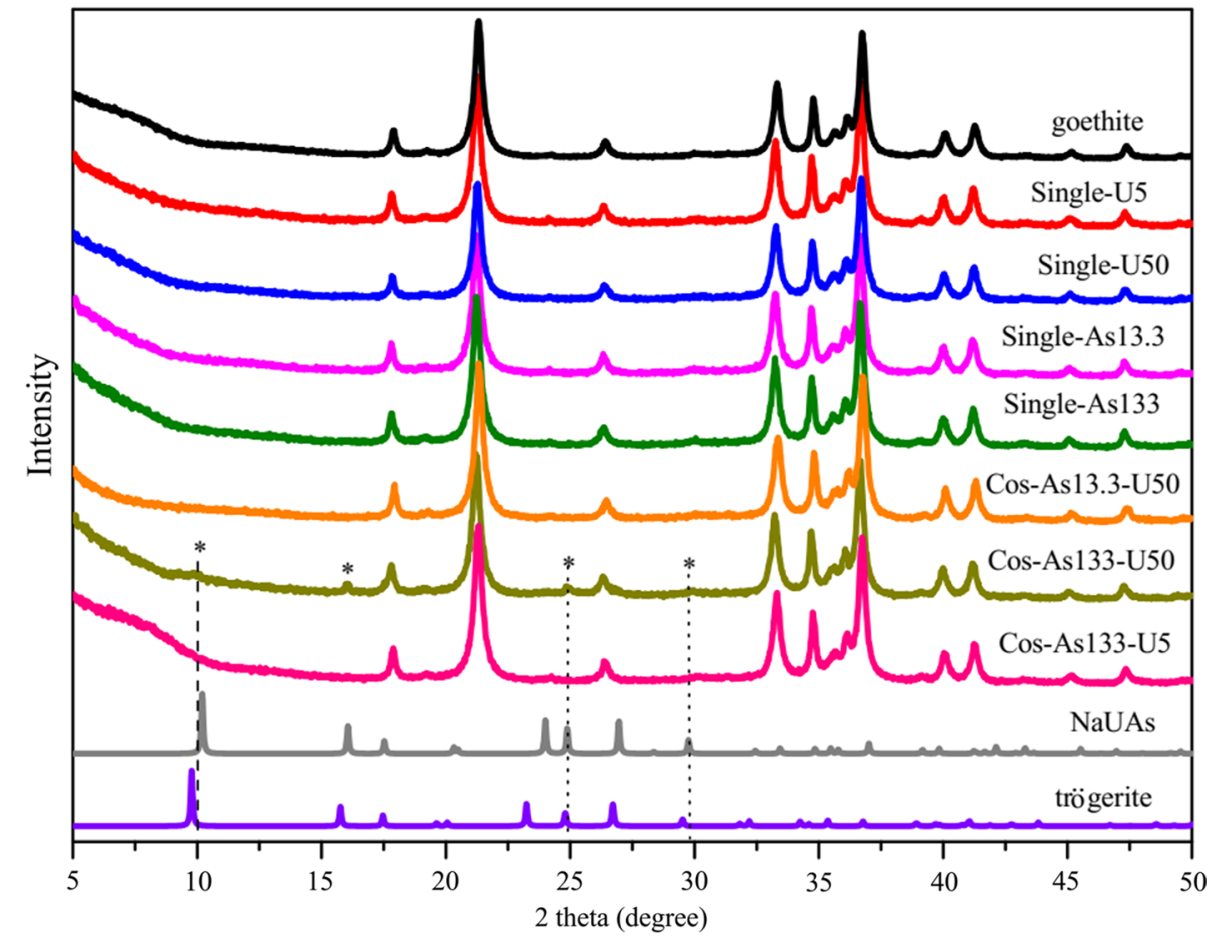

The original article can be found online at https://doi.org/10.1007/ s10967-016-5086-9.

Shitong Yang

shitongyang@suda.edu.cn

$\triangle$ Shuao Wang

shuaowang@ suda.edu.cn

1 School for Radiological and Interdisciplinary Sciences

(RAD-X), Soochow University, Suzhou 215123,

People's Republic of China
2 Collaborative Innovation Center of Radiation Medicine of Jiangsu Higher Education Institutions, Suzhou 215123, People's Republic of China

3 School of Environment and Chemical Engineering, North China Electric Power University, Beijing 102206, People's Republic of China 
Publisher's Note Springer Nature remains neutral with regard to jurisdictional claims in published maps and institutional affiliations. 